\title{
Urinary lithiasis: evaluation of the use of laser vs. Pneumatic ureteral lithotripsy
}

\author{
Ernesto Reggio ${ }^{1}$ \\ Alexandre Danilovic ${ }^{1}$ \\ Claudio Rubira ${ }^{1}$ \\ (iD) Antonio Silvinato ${ }^{1}$
}

Wanderley Marques Bernardo²

1. Sociedade Brasileira de Urologia, Rio de Janeiro, RJ, Brasil 2. Coordenador do Programa Diretrizes da Associação Médica Brasileira, São Paulo, SP, Brasil

Contact:wmbernardo@usp.br

http://dx.doi.org/10.1590/1806-9282.66.2.108

Question: In the treatment of urinary lithiasis by ureterolithotripsy, is the use of a laser energy source superior to the conventional one (pneumatic)?

Answer: In patients with urinary lithiasis and stones $<20 \mathrm{~mm}$ affecting the ureter. There is no difference in the procedure time and the need for ureteral stent between the two types of treatment (laser and pneumatic ureterolithotripsy). The laser treatment offers increased rates of therapeutic success and stone free rate outcomes and reduces the risk of complications when compared with pneumatic ureterolithotripsy ${ }^{\mathbf{1}}$.

\section{REFERENCE}

1 Reggio E, Danilovic A, Rubira C, Silvinato A, Bernardo WM. Urinary lithiasis: evaluation of the use of laser vs. Pneumatic ureteral lithotripsy Rev Assoc Med Bras 2019;65(11);1329-1335 